\title{
A Specific Multi-Nutrient Diet Reduces Alzheimer-Like Pathology in Young Adult $\mathrm{A} \beta \mathrm{PP}_{\mathrm{swe}} / \mathrm{PS}_{\mathrm{dE} 9}$ Mice
}

\author{
Laus M. Broersen ${ }^{\mathrm{a}, *}$, Almar A.M. Kuipers ${ }^{\mathrm{a}}$, Martin Balvers ${ }^{\mathrm{a}}$, Nick van Wijk ${ }^{\mathrm{a}}$, Paul J.M. Savelkoul ${ }^{\mathrm{a}}$, \\ Martijn C. de Wilde ${ }^{a}$, Eline M. van der Beek ${ }^{a}$, John W.C. Sijben ${ }^{a}$, Robert J.J. Hageman ${ }^{a}$, \\ Patrick J.G.H. Kamphuis ${ }^{\mathrm{a}, \mathrm{b}}$ and Amanda J. Kiliaan ${ }^{\mathrm{c}}$ \\ ${ }^{a}$ Nutricia Advanced Medical Nutrition, Danone Research, Centre for Specialised Nutrition, \\ Wageningen, The Netherlands \\ ${ }^{\mathrm{b}}$ Utrecht Institute for Pharmaceutical Sciences (UIPS), University Utrecht, Utrecht, The Netherlands \\ ${ }^{\mathrm{c}}$ Department of Anatomy, Radboud University Nijmegen Medical Centre, Donders Institute for Neuroscience, \\ Nijmegen, The Netherlands
}

Handling Associate Editor: Danny Michaelson

Accepted 20 July 2012

\begin{abstract}
Diet is an important lifestyle factor implicated in the etiology of Alzheimer's disease (AD), but so far it is not fully elucidated to which nutrients the suggested protective effect of diet can be attributed. Recent evidence obtained in the amyloid- $\beta$ $1-42\left(\mathrm{~A} \beta_{42}\right)$ infusion model in rats has shown that a multi-nutrient intervention known as Fortasyn ${ }^{\mathrm{TM}}$ Connect (FC) may protect the central cholinergic system against $\mathrm{A} \beta_{42}$-induced toxicity. FC comprises the nutritional precursors and cofactors for membrane synthesis, viz. docosahexaenoic acid (DHA), eicosapentaenoic acid, uridine-mono-phosphate (UMP), choline, phospholipids, folic acid, vitamins B6, B12, C, E, and selenium. In order to investigate whether the combined administration of these nutrients may also affect $\mathrm{AD}$-like pathology, we now evaluated the effects of the FC diet intervention in the transgenic $\mathrm{A} \beta \mathrm{PP} \mathrm{swe}_{\mathrm{sw}} / \mathrm{PS}_{\mathrm{dE}}$ mouse model with endogenous $A \beta$ production. In addition we evaluated the effects of diets containing the individual nutrients DHA and UMP and their combination in this model. Between the age of 3 and 6 months, FC diet decreased brain A $\beta$ levels and amyloid plaque burden in the hippocampus of A $\beta P P / P S 1$ mice. The FC diet also reduced ongoing disintegrative degeneration in the neocortex, as indicated by Amino Cupric Silver staining. Although all three DHA-containing diets were equally effective in changing brain fatty acid profiles, diets differentially affected amyloid-related measures, indicating that effects of DHA may depend on its dietary context. The current data, showing that dietary enrichment with FC reduces AD-like pathology in $\mathrm{A} \beta \mathrm{PP} / \mathrm{PS} 1$ mice, confirm and extend our previous findings in the $\mathrm{A} \beta_{42}$ infusion model and favor the combined administration of relevant nutrients.
\end{abstract}

Keywords: AßPP/PS1 transgenic mice, Alzheimer's disease, amyloid- $\beta$, degenerative staining, DHA, Fortasyn Connect, nutrition, plaque burden, souvenaid, UMP

\footnotetext{
${ }^{*}$ Correspondence to: Laus M. Broersen, Nutricia Advanced Medical Nutrition, Danone Research, Centre for Specialised Nutrition, PO Box 7005, 6700 CA Wageningen, The Netherlands. Tel.: +31 317467 854; Fax: +31 317466 500; E-mail: laus.broersen@ nutricia.com.
}

\section{INTRODUCTION}

Diet is an important lifestyle factor implicated in the etiology of dementias including Alzheimer's disease (AD). Specific dietary patterns are associated with lower risks of developing dementias [1-5], and 
adherence to complex dietary compositions has been associated with better mental and physical health [6] and reduced risk of developing AD [7, 8]. The potentially protective effects of diet, however, cannot easily be attributed to the actions of individual nutrients, as a variety of systematic reviews conclude that single-nutrient interventions are predominantly nonsuccessful [9-12]. Presumably, the combined intake of such nutritional components is required in order to reach efficacy.

A striking example of the added value that the simultaneous enrichment of nutrients can have comes from a series of experiments showing that the combination of the phospholipid precursors docosahexaenoic acid (DHA) and uridine-mono-phosphate (UMP) can act synergistically in stimulating membrane phospholipid synthesis, increasing dendritic spine density, and improving learning and memory [13-15]. The nutrients work by increasing the substrate-saturation of low-affinity enzymes that synthesize the phospholipids [16]. All these observations were made in healthy rodents, but the effects reported are considered to be very relevant for $\mathrm{AD}$, in which brain phospholipids are reduced $[17,18]$ and which is characterized by a loss of synaptic connections $[19,20]$ thought to underlie the loss of cognitive functioning. In line with this suggestion, we recently reported that a multi-nutrient composition called Fortasyn ${ }^{\mathrm{TM}}$ Connect $(\mathrm{FC})$ protected the central cholinergic system against amyloid- $\beta$ 1-42 $\left(\mathrm{A} \beta_{42}\right)$-induced toxicity in a membrane toxicity model of $A D$, the $A \beta_{42}$ infused rat [21]. Based on this, we were interested to see whether combined administration of nutrients that affect membrane synthesis and composition may also affect endogenous membrane-bound processes relevant to $A D$, such as $A \beta$ production and amyloid plaque formation.

The aim of the present study was to investigate the effects of nutritional interventions on the development of AD-like pathological changes in female transgenic A $\beta P P / P S 1$ mice. These female mice show A $\beta$ plaque formation as early as $4-5$ months of age [22, 23], which is sensitive to dietary manipulations [24]. We carried out two experiments in which dietary interventions were started at the age of 3 months and continued for another 3 months. In both experiments, effects of diets were assessed on brain composition and pathology, using A $\beta$ ELISA, fatty acid analysis, as well as immunohistochemical techniques to assess amyloid plaque burden $\left(A \beta_{42}\right.$ stain) and ongoing degenerative burden (deOlmos Amino Cupric Silver stain $[25,26])$.
In a first experiment we evaluated the effects of the multi-nutrient FC composition that was designed to stimulate synaptic membrane formation, comprising a full set of precursors and cofactors for membrane synthesis, including UMP, DHA, eicosapentaenoic acid (EPA), choline, vitamin B6, vitamin B12, folic acid, phospholipids, vitamin $\mathrm{C}$, vitamin $\mathrm{E}$, and selenium. From these nutrients, UMP, DHA, and choline are all precursors for the Kennedy cycle for phospholipid synthesis [16, 27]. Dietary EPA contributes as a precursor to raise brain levels of DHA [28, 29]. The phospholipids act both as precursors and cofactors, by providing choline and diacylglycerol (DAG) for the Kennedy cycle and by enhancing the availability of DHA, respectively. The remaining cofactors, i.e., the B-vitamins and the antioxidants, are necessary to enable and support the biochemical processes involved in phospholipid synthesis and/or to increase the availability of the membrane precursors, either by stimulating the endogenous synthesis or by reducing their degradation (e.g., $[30,31])$. In addition, selenium may enhance PC synthesis by increasing the activity of a key enzyme in the Kennedy cycle, CDPcholine:DAG cholinephosphotransferase [32]. Levels of choline, phospholipids, and polyunsaturated fatty acids like DHA are known to be decreased in the brains of $\mathrm{AD}$ patients [17, 18,33], and epidemiological studies have reported that $\mathrm{AD}$ patients also have lower plasma levels of DHA, folic acid, vitamin B12, vitamin $\mathrm{E}$, and vitamin $\mathrm{C}$ as compared to age-matched controls [34-36]. The effects of the FC diet intervention were studied both in A $\beta P P / P S 1$ mice and their wild type littermates.

In a second experiment we evaluated the effects of diets that were supplemented with either DHA or UMP or the combination of these two nutrients in transgenic mice. DHA may reduce $A \beta$ release by directing amyloidogenic processing of $A \beta$ protein precursor $(A \beta P P)$ toward non-amyloidogenic processing [37]. DHA has been evaluated before in various transgenic mouse models of AD pathology [24, 38, 39], but has not always been found to affect amyloid production or plaques [40, 41]. It has been suggested that the efficacy of DHA in reducing amyloid plaque formation may depend on its dietary context [42]. UMP has not been evaluated before in transgenic mouse models of $\mathrm{AD}$, but has repeatedly been shown to act synergistically in combination with DHA on structural brain changes in healthy rodents $[15,16]$. We now tested the combination of DHA and UMP to see whether these nutrients would also show synergistic effects on brain parameters in A $\beta P P / P S 1$ mice. 


\section{MATERIALS AND METHODS}

\section{Animals and dietary interventions}

The $\mathrm{A} \beta P \mathrm{P}_{\mathrm{swe}} / \mathrm{PS} 1_{\mathrm{dE} 9}$ founders were obtained from Johns Hopkins University, Baltimore, MD, USA (Borchelt and Jankowsky, Department of Pathology) and a colony was established at the Radboud University Nijmegen Medical Centre, The Netherlands. The mice had been created by co-injection of chimeric mouse/human A $\beta P P s w e$ (mouse A 3 PP695 harboring a human $A \beta$ domain and mutations K595N and M596L linked to Swedish familial AD pedigrees) and human PS1-dE9 (deletion of exon 9) vectors controlled by independent mouse prion protein promoter elements. This line (line 85 [22]) was originally maintained in a hybrid background by backcrossing to $\mathrm{C} 3 \mathrm{HeJ} \times \mathrm{C} 57 \mathrm{~B} 16 / \mathrm{J}$ F1 mice. For the present work, the breeder mice were backcrossed to C57B16/J for 9 generations.

Female A $\beta P P / P S 1$ transgenic mice and wild type littermate controls were housed in groups of 4-6 animals per cage. The animals were kept in a controlled environment, with temperature at $20-22^{\circ} \mathrm{C}$, humidity at $50-60 \%$, and lights on between 07:00 and 19:00 h. Food and water were freely available throughout the study. Some animals died for unknown reasons during the study, and were discarded from the experiment.

At the age of 3 months, the mice were subjected to the experimental diets for a period of 3 months, as indicated in Table 1 . In experiment $\mathrm{A}$, both wild type and transgenic mice were fed with either a Control diet or a FC diet. In experiment B, groups of transgenic mice were fed DHA, UMP, or DHA + UMP diets. Experiment $\mathrm{B}$ was conducted to test the individual and combined effects of DHA and UMP supplementation. The diets differed in composition with regard to the fat blends used, as well as a number of supplemented nutrients as indicated in Tables 2 and 3. The source of DHA was fish oil (tuna, Numega, and EPA-28SP; Lithos Foods). All diets were isoenergetic, were based on the Control diet, fulfilled all dietary requirements, and were manufactured and pelleted by Research Diet Services (Wijk bij Duurstede, The Netherlands). All diets were stored at $-20^{\circ} \mathrm{C}$ until use, in order to prevent oxidation of lipids. Reanalysis of the diets at the end of the study confirmed that all fatty acids were still present in the original amounts.

All animal experimental protocols were conducted in accordance with European and Dutch laws and institutional guidelines and approved by the local
Table 1

Overview of groups of mice and the experimental diets for experiments $\mathrm{A}$ and $\mathrm{B}$

\begin{tabular}{llcc}
\hline Experiment & Genotype & Diet & \# mice \\
\hline A & Wild type & Control & 11 \\
& & FC & 10 \\
& Transgenic & Control & 7 \\
& & FC & 7 \\
B & & Control & 7 \\
& Transgenic & DHA & 5 \\
& & UMP & 8 \\
& & DHA + UMP & 7 \\
\hline
\end{tabular}

ethics committee (DEC Consult, Bilthoven, The Netherlands).

\section{Tissue preparation}

At the age of 6 months, mice were perfused transcardially with ice-cold saline containing 5.8 mM EDTA under deep sodium pentobarbital anesthesia. Brains were rapidly removed and divided at the midline. The left hemisphere was snap frozen in liquid nitrogen and stored at $-80^{\circ} \mathrm{C}$ until freeze drying (Virtis Advantage EL, Depex) for A $\beta$ ELISA and fatty acid analysis. Freeze dried hemispheres were grinded in a mixer mill (Retsch, MM200) for $45 \mathrm{~s}$ at $20 \mathrm{~Hz}$ and the tissue was stored at $-20^{\circ} \mathrm{C}$ until further analysis. The right hemisphere was fixed in $4 \%$ paraformaldehyde for $24 \mathrm{~h}$ and then rinsed in PBS and stored in PBS with $0.1 \%$ azide until further processing for histological analyses.

\section{A $\beta$ ELISA}

For the human $A \beta$ ELISA assay on brain samples of transgenic mice, $20 \mathrm{mg}$ of grinded freeze dried brain tissue was homogenized in $200 \mu \mathrm{L}$ PBS (Invitrogen). The homogenate was centrifuged at $13,000 \mathrm{rpm}$, $10 \mathrm{~min}$ at $4^{\circ} \mathrm{C}$. The supernatant was removed. The pellet was resuspended in $80 \mu \mathrm{L} 4 \times$ formic acid (VWR International) and sonicated for $10 \mathrm{~min}$. The sample was neutralized by adding $720 \mu \mathrm{L} 4 \mathrm{M}$ Tris. After centrifuging $\left(13.000 \mathrm{rpm}, 10 \mathrm{~min}\right.$ at $\left.4^{\circ} \mathrm{C}\right)$, the supernatant was used to detect $A \beta$, using the hAmyloid $\beta 42$ Brain ELISA and the hAmyloid $\beta 40$ Brain ELISA (Genetics Company, TKbrain-Set). According to the manufacturer's protocol, a standard curve was made with a range of $25-500 \mathrm{pg} / \mathrm{ml}$. The samples were diluted $50-100 \times$ using the dilution buffer supplied by the manufacturer. $50 \mu \mathrm{L}$ of antibody conjugate solution was added to the 96 wells plate before $50 \mu \mathrm{L}$ of standard or sample was added. The plates were covered and mixed thoroughly on a plate shaker. After an overnight incu- 
Table 2

Detailed compositions of the experimental diets that were used in experiments A and B. All diets were isoenergetic, contained 5\% fat (oli blend specified in Table 3), and also contained standard vitamin and mineral premix, providing recommended daily amounts of these nutrients. Specific nutrients or combinations of nutrients that were supplemented on top of the standard Control diet are indicated in the lower part of the table (UMP through Vit.B12). All amounts of nutrients are indicated in $\mathrm{g} / 100 \mathrm{~g}$ of diet. All diets were presented to the animals as pellets

\begin{tabular}{|c|c|c|c|c|c|c|}
\hline \multirow[t]{2}{*}{ Ingredients ( $\mathrm{g} / 100 \mathrm{~g}$ diet) } & \multicolumn{2}{|c|}{ Experiment A } & \multicolumn{4}{|c|}{ Experiment B } \\
\hline & Control & $\mathrm{FC}$ & Control & DHA & UMP & $\mathrm{DHA}+\mathrm{UMP}$ \\
\hline Wheat & 25.87 & 23.82 & 25.87 & 25.87 & 24.87 & 24.87 \\
\hline Barley & 25.00 & 25.00 & 25.00 & 25.00 & 25.00 & 25.00 \\
\hline Semolina & 25.00 & 25.00 & 25.00 & 25.00 & 25.00 & 25.00 \\
\hline Soybean meal & 8.50 & 8.50 & 8.50 & 8.50 & 8.50 & 8.50 \\
\hline Whey & 5.00 & 5.00 & 5.00 & 5.00 & 5.00 & 5.00 \\
\hline Bentonite & 1.00 & 1.00 & 1.00 & 1.00 & 1.00 & 1.00 \\
\hline Vitamin/mineral premix & 2.20 & 2.20 & 2.20 & 2.20 & 2.20 & 2.20 \\
\hline $\mathrm{CaCO}_{3}$ & 1.40 & 1.40 & 1.40 & 1.40 & 1.40 & 1.40 \\
\hline Dicalciumphosphate & 0.30 & 0.30 & 0.30 & 0.30 & 0.30 & 0.30 \\
\hline $\mathrm{NaCl}$ & 0.50 & 0.50 & 0.50 & 0.50 & 0.50 & 0.50 \\
\hline L-lysine $\mathrm{HCl}$ & 0.18 & 0.18 & 0.18 & 0.18 & 0.18 & 0.18 \\
\hline DL-methionine & 0.05 & 0.05 & 0.05 & 0.05 & 0.05 & 0.05 \\
\hline Oil blend & 5.00 & 5.00 & 5.00 & 5.00 & 5.00 & 5.00 \\
\hline Providing DHA & - & 0.757 & - & 0.757 & - & 0.757 \\
\hline Providing EPA & - & 0.189 & - & 0.189 & - & 0.189 \\
\hline UMP & - & 1.000 & - & - & 1.000 & 1.000 \\
\hline Choline & - & 0.313 & - & - & - & - \\
\hline Lecithin & - & 0.412 & - & - & - & - \\
\hline Vitamin E & - & 0.157 & - & - & - & - \\
\hline Vitamin C & - & 0.160 & - & - & - & - \\
\hline Selenium & - & 0.000111 & - & - & - & - \\
\hline Folic acid & - & 0.0007 & - & - & - & - \\
\hline Vitamin B6 & - & 0.0027 & - & - & - & - \\
\hline Vitamin B12 & - & 0.0000011 & - & - & - & - \\
\hline
\end{tabular}

Table 3

Specification of the oil blends that were used for the various diets in experiments A and B. All diets contained $5 \%$ of fat. Relative amounts of saturated fatty acids (SFA), mono-unsaturated fatty acids (MUFA), and poly-unsaturated fatty acids (PUFA) were similar for all diets

\begin{tabular}{|c|c|c|c|c|c|c|c|}
\hline & & \multicolumn{2}{|c|}{ Experiment A } & \multicolumn{4}{|c|}{ Experiment B } \\
\hline & & Control & $\mathrm{FC}$ & Control & DHA & UMP & DHA UMP \\
\hline \multirow[t]{4}{*}{ Source } & Soy oil & 1.39 & & 1.39 & & 1.39 & \\
\hline & Coconut oil & 0.65 & 0.10 & 0.65 & 0.10 & 0.65 & 0.10 \\
\hline & Corn oil & 2.96 & 1.75 & 2.96 & 1.75 & 2.96 & 1.75 \\
\hline & Fish oil & & 3.15 & & 3.15 & & 3.15 \\
\hline \multirow[t]{3}{*}{$\% \mathrm{FA}$} & SFA & 24 & 26 & 24 & 26 & 24 & 26 \\
\hline & MUFA & 24 & 24 & 24 & 24 & 24 & 24 \\
\hline & PUFA & 52 & 49 & 52 & 49 & 52 & 49 \\
\hline
\end{tabular}

bation at $4^{\circ} \mathrm{C}$, the plates were washed 5 times with the supplied washing buffer. $100 \mu \mathrm{L}$ of enzyme conjugate was added to wells for 30 min incubation at room temperature. The plate was washed 5 times and subsequently $100 \mu \mathrm{L}$ of substrate was added. After $25 \mathrm{~min}$ incubation in the dark at room temperature, $50 \mu \mathrm{L}$ of stop solution was added and the plates were measured at $450 \mathrm{~nm}$ with a reference filter of $620-650 \mathrm{~nm}$.

\section{Histology}

The fixed hemispheres were processed by NeuroScience Associates (Knoxville, USA), who subsequently stained two adjacent series of sections. One series of sections was subjected to an immunohistochemical staining with an antibody for $A \beta_{1-42}$ to reveal amyloid plaques. Another series of sections was stained with the deOlmos Amino Cupric Silver method to reveal ongoing disintegrative degeneration $[25,26]$. In short, hemispheres, arranged in $4 \times 8$ arrays, were embedded in a gelatin matrix using MultiBrain ${ }^{\circledR}$ Technology. Each block of embedded hemispheres was rapidly frozen by immersion in isopentane chilled to $-70^{\circ} \mathrm{C}$ with crushed dry ice. Frozen sections $(35 \mu \mathrm{m})$ were then cut in the coronal plane throughout the striatum-hippocampus part of the 
hemispheres. Sections to be stained with the A $\beta$ antibody were stored in antigen preserve storage buffer; the sections to be stained with the Amino Cupric Silver method were stored in Fix-storage buffer.

\section{Image analysis}

Images of the stained sections were obtained by using. Slide (Olympus, Zoeterwoude, The Netherlands) and image analyses were performed with AnalySIS Five (Olympus). Using the unbiased sampling method, regions of interest (ROI) were selected in the scanned sections for both the hippocampus and the overlying neocortex. Surface areas were stereologically quantified using the Cavalieri method. Total area stained per ROI was determined by densitometric measurements and expressed as plaque burden (A $\beta_{1-42}$ staining) or degenerative burden (visualized with deOlmos Amino Cupric Silver stain for disintegrative degeneration), calculated as the ratio of stained surface and total ROI surface for each respective brain area (hippocampus or neocortex).

\section{Brain fatty acid analysis}

Fatty acid analyses were performed on $20 \mathrm{mg}$ of the grinded freeze dried brain tissue that was homogenized in $1 \%$ EDTA solution. Total lipid content was extracted from the homogenates by adding methanol and dichloromethane. Subsequently, samples were centrifuged at $3000 \mathrm{rpm}$ for $10 \mathrm{~min}$ and the lower layer (dichloromethane and lipids) was collected. $200 \mu \mathrm{l}$ of the dichloromethane layer was evaporated to dryness in a SpeedVac $\AA$ concentrator. $2 \mathrm{~mL}$ methanol and $40 \mu \mathrm{L}$ concentrated sulfuric acid were added to the dried extract. The samples were heated at $100^{\circ} \mathrm{C}$ for $60 \mathrm{~min}$, and $2 \mathrm{~mL}$ hexane and $0.5 \mathrm{~mL} 2.5 \mathrm{M}$ sodium hydroxide solution were added. After vortexing and centrifuging the samples for $5 \mathrm{~min}$ at $3000 \mathrm{rpm}$, the upper layer was collected and evaporated in a SpeedVac®. The fatty acids were dissolved in $125 \mu \mathrm{L}$ iso-octane and analyzed on a GC-FID with a CP-SIL88 column $(50 \mathrm{~m} \times 0.25 \mathrm{~mm}$ id. $0.22 \mu \mathrm{m}$ film thickness $)$.

\section{Statistics}

All statistical analyses were performed using SPSS 15.0 (SPSS Benelux). Effects of the different diets on body weight were analyzed using repeated measures ANOVA with Weeks having 13 levels as within-subject variable. Between-subject variables in experiment A consisted of Genotype (transgenic and wild type) and/or Diet (Control and FC). In experiment B, the between-subject variable Diet had 4 levels (Control, DHA, UMP, and DHA + UMP). Effects of diets on A $\beta$ ELISA, amyloid plaque burden, and degenerative burden were analyzed using univariate ANOVA. Effects of diets on brain fatty acid profiles were analyzed using multivariate ANOVA. For all analyses, differences were considered significant at $p<0.05$. Post hoc comparisons were performed when appropriate. Next to the primary statistical analyses according to the original experimental design, a posteriori exploratory statistical analyses were performed using ANOVA to compare effects of FC diet (experiment A) and DHA + UMP diet (experiment $\mathrm{B}$ ) on $\mathrm{A} \beta$ pathology in transgenic mice.

\section{RESULTS}

\section{Body weights}

In both experiment $\mathrm{A}$ and $\mathrm{B}$, body weights increased over Weeks $(\mathrm{F}(12,372)=79.95 ; p<0.001$ and $\mathrm{F}(12,276)=94.63 ; p<0.001$, respectively). No main effect of Genotype, Diet, or their interaction was found to be significant. A significant Genotype $\mathrm{x}$ Weeks interaction in experiment $\mathrm{A}(\mathrm{F}(12,372)=3.45$; $p<0.001)$ indicated that weight gain over time was larger in wild type mice, irrespective of Diet.

\section{Amyloid and related pathological changes: experiment $A$}

Data obtained in experiment A with respect to brain amyloid parameters are displayed in Fig. 1.

\section{A $\beta$ ELISA}

In brain homogenates of transgenic mice, the FC diet significantly reduced both the levels of $\mathrm{A} \beta_{42}\left(\mathrm{~F}(1,12)=6.28 ; p<0.05 ;\right.$ Fig. 1a) and $A \beta_{40}$ $(\mathrm{F}(1,12)=5.81 ; p<0.05$; Fig. $1 \mathrm{~b})$ as compared to Control diet.

\section{Amyloid plaque burden}

A $\beta P P / P S 1$ transgenic mice had a higher amyloid plaque burden in the hippocampus than wild type mice $(\mathrm{F}(1,31)=334.4 ; p<0.001 ;$ Fig. $1 \mathrm{c})$. The FC diet reduced the amyloid plaque burden in the hippocampus compared to the Control diet $(\mathrm{F}(1,31)=6.28$; $p<0.02)$. A significant Diet $\mathrm{x}$ Genotype interaction $(\mathrm{F}(1,31)=6.22 ; p<0.02)$ was found. Post-hoc analyses showed no significant effect of Diet in wild type mice $(p=0.68)$. Similar to the hippocampus, the amyloid plaque burden in the neocortex of transgenic mice was 

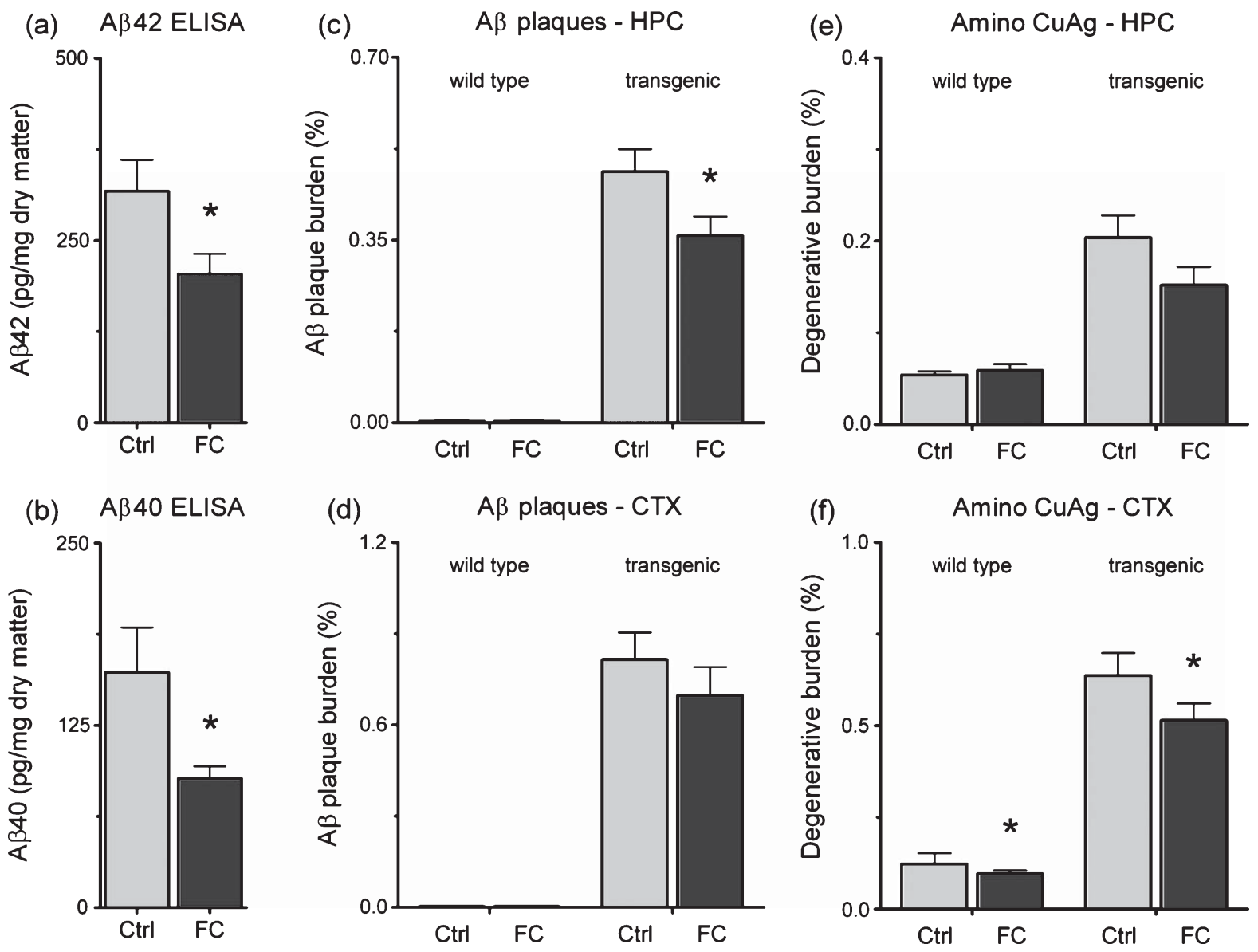

Fig. 1. Effects of Control and FC diets on brain amyloid related parameters in A $\beta P P / P S 1$ transgenics and their wild type mice in experiment A. All graphs display means (+SEM). Graphs on the left display levels of $A \beta_{42}$ (a) and $A \beta_{40}$ (b) as measured by ELISA in freeze dried brain homogenates from transgenic mice. Graphs in the middle display percentage amyloid plaque burden as indicated by $A \beta_{42}$ staining in the hippocampus (HPC, c) and the neocortex (CTX, d) of wild type and transgenic mice. Graphs on the right display percentage degenerative burden as indicated by Amino Cupric Silver staining in the hippocampus (HPC, e) and the neocortex (CTX, f) of wild type and transgenic mice. Dietary interventions are indicated at the $\mathrm{x}$-axes. ${ }^{*} p<0.05$ versus Control.

elevated in comparison to wild types $(\mathrm{F}(1,31)=204.4$; $p<0.001$; Fig.1d). The FC diet did not affect amyloid plaque burden in the neocortex $(p=0.48)$.

\section{Degenerative burden}

Although some ongoing degeneration was present in the brains of all mice, the degenerative burden in transgenic mice was significantly increased in both the hippocampus $(\mathrm{F}(1,31)=97.3 ; p<0.001$; Fig. 1e $)$ and the neocortex $(\mathrm{F} 1,31)=169.4 ; p<0.001$; Fig. 1f $)$ as compared to wild type mice. The FC diet did not affect degenerative burden in the hippocampus $(\mathrm{F}(1,31)=1.75 ; p=0.195)$. In the neocortex, however, the FC diet induced a significant decrease in degenerative burden $(\mathrm{F}(1,31)=4.44 ; p<0.05)$, irrespective of Genotype.
Representative illustrations of plaque burden $(A \beta)$ and degenerative burden (Amino $\mathrm{CuAg}$ ) in the brains of animals from experiment $\mathrm{A}$ are given in Fig. 2 .

\section{Amyloid and related pathological changes: experiment $B$}

Data obtained in experiment B with respect to brain amyloid parameters are displayed in Fig. 3 .

\section{A $\beta$ ELISA}

The dietary interventions affected brain levels of $\mathrm{A} \beta_{42}\left(\mathrm{~F}(3,23)=3.67 ; p<0.05\right.$; Fig. 3a) and $\mathrm{A} \beta_{40}$ $\left(F(3,23)=3.63 ; p<0.05\right.$; Fig. 3b). Levels of $A \beta_{42}$ in the DHA + UMP group were higher than those in the DHA and UMP groups (both $p<0.05$ ). Levels of $A \beta_{40}$ 

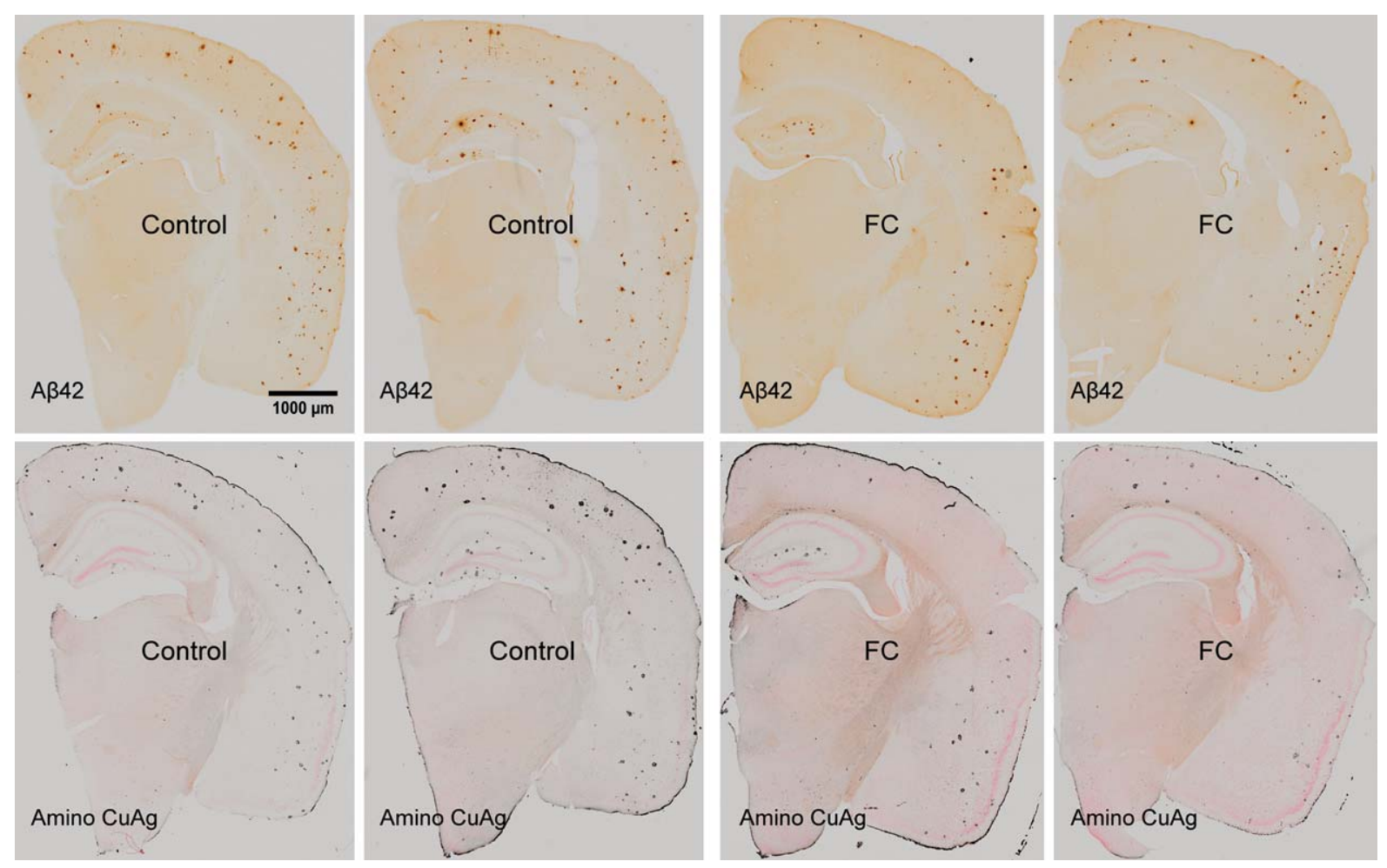

Fig. 2. Representative images of $A \beta_{42}$ ( $A \beta$; top row) and deOlmos Amino Cupric Silver (Amino CuAg; bottom row) staining in brain sections from A $\beta P P / P S 1$ mice of experiment A. Images on the left show amyloid plaques and associated degenerative staining in adjacent sections in a mouse on the Control diet. Images on the right are taken from adjacent sections in a mouse on the FC diet. Group means of plaque burden and degenerative burden in hippocampus and neocortex are shown in Fig. 1c-f. The FC diet reduced plaque burden in the hippocampus and degenerative burden in the neocortex.

were reduced by the UMP diet as compared to both the Control and the DHA + UMP diets (both $p<0.05$ ).

\section{Amyloid plaque burden}

Dietary interventions with DHA, UMP, or DHA + UMP in A $\beta P P / P S 1$ transgenic mice did not induce significant changes in amyloid plaque burden as compared to the Control diet in either the hippocampus $(\mathrm{F}(3,23)=1.16 ; p=0.35$; Fig. 3c $)$ or the neocortex $(\mathrm{F}(3,23)=1.36 ; p=0.28$; Fig. 3d). Representative illustrations of plaque burden in the brains of animals from experiment B are given in Fig. 4.

\section{Degenerative burden}

Degenerative burden in the hippocampus was not significantly affected by dietary interventions with DHA, UMP, or DHA + UMP in A $\beta P P / P S 1$ transgenic mice $(\mathrm{F}(3,23)=2.09 ; p=0.129$; Fig. 3e $)$. Similarly, the latter diets did not affect degenerative burden in the neocortex $(\mathrm{F}(3,23)=0.80 ; p=0.506$; Fig. 3f).

\section{A posteriori exploratory comparisons: experiments $A$ and $B$}

Next to the primary statistical analyses according to the original experimental design, it was decided to perform some a posteriori exploratory statistical analyses. For the measures related to $A \beta$ pathology in transgenic mice, the effects of the FC diet in experiment $\mathrm{A}$ were directly compared to the effects of the DHA + UMP diet in experiment B. These comparisons were considered relevant in the light of the original aim concerning potential synergistic actions of nutrients. The results of the analyses indicated that, compared to the DHA + UMP diet, the FC diet resulted in significantly lower levels of $\mathrm{A} \beta_{42}(\mathrm{~F}(1,12)=11.20$; $p<0.01)$ and $\mathrm{A} \beta_{40}(\mathrm{~F}(1,12)=50.19 ; p<0.001)$, and a lower amyloid plaque burden in the hippocampus $(\mathrm{F}(1,12)=5.02 ; p<0.05)$ but not in the neocortex $(p=0.36)$. As compared to the DHA + UMP diet, the FC diet resulted in significantly lower degenerative burden in the hippocampus $(\mathrm{F}(1,12)=6.33 ; p<0.05)$ 

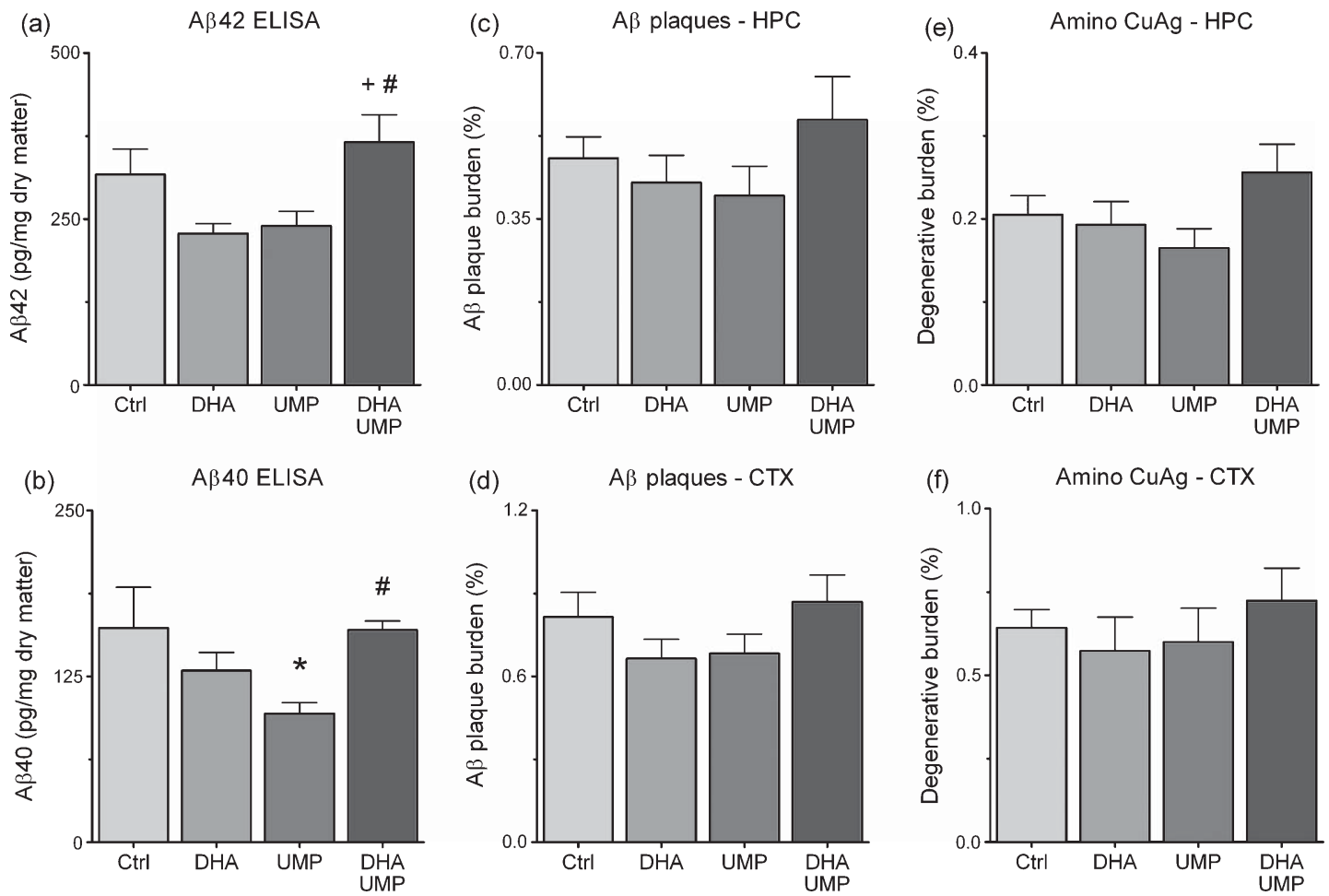

Fig. 3. Effects of Control, DHA, UMP, and DHA + UMP diets on brain amyloid related parameters in A $\beta P P / P S 1$ transgenics mice in experiment B. All graphs display means (+SEM). Graphs on the left display levels of $A \beta_{42}$ (a) and $A \beta_{40}$ (b) as measured by ELISA in freeze dried brain homogenates. Graphs in the middle display percentage amyloid plaque burden as indicated by A $\beta_{42}$ staining in the hippocampus (HPC, c) and the neocortex $(\mathrm{CTX}, \mathrm{d})$. Graphs on the right display percentage degenerative burden as indicated by Amino Cupric Silver staining in the hippocampus (HPC, e) and the neocortex (CTX, f). Dietary interventions are indicated at the x-axes. ${ }^{*} p<0.05$ versus Control; ${ }^{+} p<0.05$ versus DHA; ${ }^{*} p<0.05$ versus UMP.

and marginally lower degenerative burden in the neocortex $(\mathrm{F}(1,12)=3.82 ; p=0.07)$.

\section{Brain fatty acids}

The relative amounts of different fatty acids in the lipid fraction of the brain homogenates from experiment $\mathrm{A}$ and $\mathrm{B}$ are displayed in Tables 4 and 5, respectively.

In experiment A (Table 4), small differences between brain fatty acid profiles of A $\beta P P / P S 1$ transgenic and wild type mice were noted. Main effects of Genotype were found for 18:0 (stearic acid; $\mathrm{F}(1,31)=5.31 ; \quad p<0.05$ ), $18: \ln 9 \quad$ (oleic acid; $\mathrm{F}(1,31)=2.90 ; p<0.05)$, and total PUFAs $(\mathrm{F}(1,31)=4.23 ; p<0.05)$. For $22: 6 \mathrm{n} 3$ (DHA) the Diet $\times$ Genotype interaction just failed to reach significance $(\mathrm{F}(1,31)=3.24 ; p=0.08)$, indicating that the Diet-induced increase in DHA tended to be larger in transgenic mice. The FC diet reduced n6 PUFAs
$(\mathrm{F}(1,31)=575.86 ; p<0.001)$ and increased $\mathrm{n} 3$ PUFAs $(\mathrm{F}(1,31)=125.42 ; p<0.001)$ relative to the Control diet in both A $\beta P P / P S 1$ transgenic and wild type mice. The FC diet decreased the relative amount of $20: 4 \mathrm{n} 6$ (AA; $\mathrm{F}(1,31)=626.12 ; p<0.001)$ and increased DHA $(\mathrm{F}(1,31)=694.37 ; p<0.001)$. The FC diet decreased the total relative amount of PUFAs $(\mathrm{F}(1,31)=8.00$; $p<0.01)$. The total relative amount of MUFAs was increased by the $\mathrm{FC} \operatorname{diet}(\mathrm{F}(1,31)=16.30 ; p<0.001)$, mainly due to an increase in $18: \ln 9(\mathrm{~F}(1,31)=88.39$; $p<0.001)$.

In experiment B (Table 5), the DHA diet and the DHA + UMP diet similarly affected brain fatty acid profiles as compared to both the Control diet and the UMP diet. Both DHA-containing diets decreased 18:0 $(\mathrm{F}(3,23)=3.14 ; p<0.05)$, and increased both $18: \ln 9(\mathrm{~F}(3,23)=18.27 ; p<0.001)$ and the total relative amount of MUFAs $(\mathrm{F}(3,23)=3.49$; $p<0.05)$. The DHA-containing diets decreased the n6 PUFAs $(\mathrm{F}(3,23)=178.01 ; p<0.001)$ including AA 

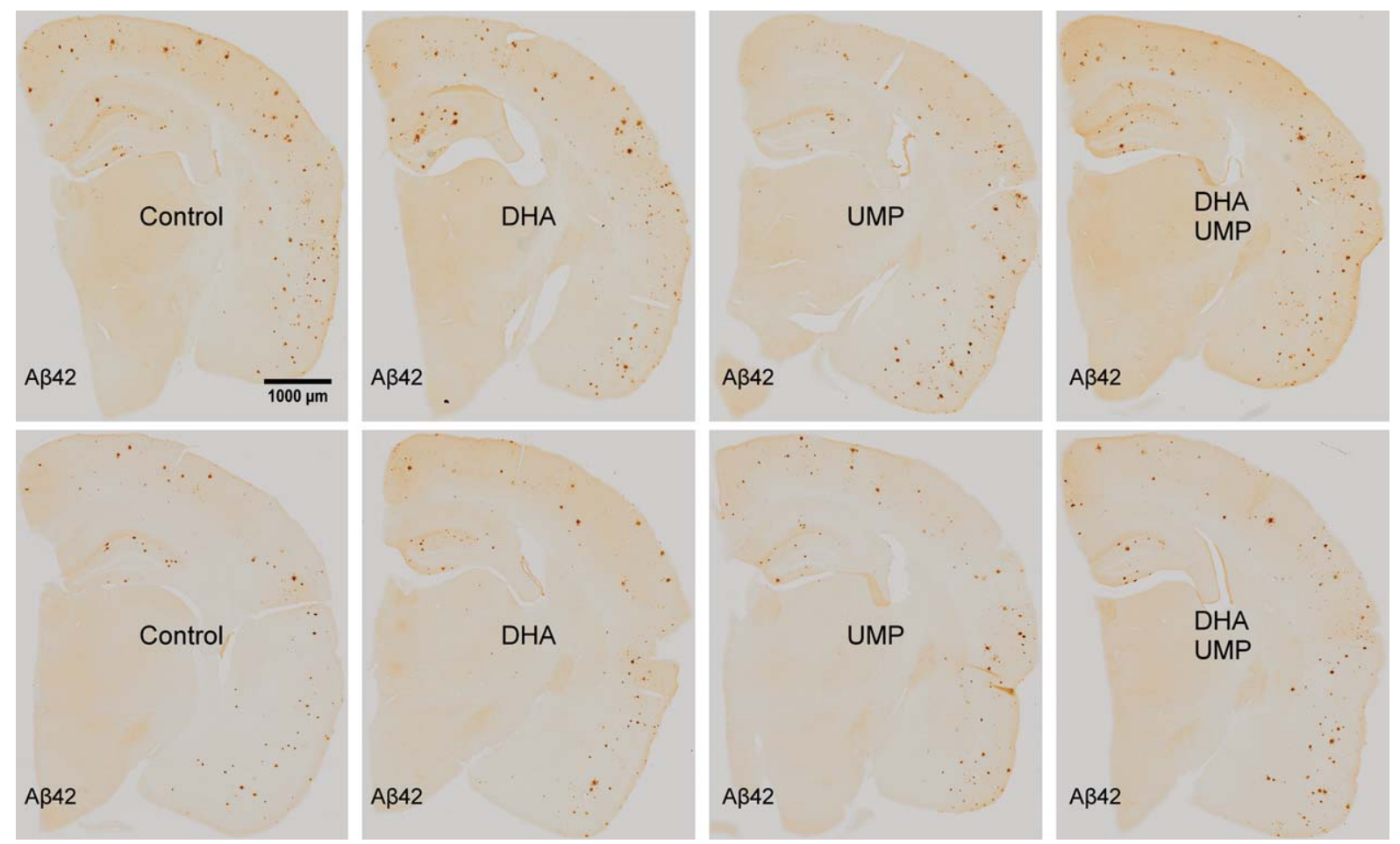

Fig. 4. Representative images of $A \beta_{42}(A \beta)$ staining in brain sections from $A \beta P P / P S 1$ mice of experiment $B$. From left to right, images from mice on the Control diet, the DHA only diet, the UMP only diet, and the DHA + UMP diet are presented. Group means of plaque burden in hippocampus and neocortex, as shown in Fig. 3c, d, were not significantly different for the Diet groups.

Table 4

Relative amounts of the major individual fatty acids and their classes in the lipid fraction of the brain homogenates from experiment A. Data are expressed as means, with SEMs within parentheses. Statistically significant main effects $(p<0.05)$ of Genotype (G) and Diets (D) are indicated at the right hand side; trends $(p<0.10)$ are indicated within parentheses

\begin{tabular}{|c|c|c|c|c|c|}
\hline \multirow[t]{2}{*}{ Expt. A } & \multicolumn{2}{|c|}{ Wild type } & \multicolumn{2}{|c|}{ Transgenic } & \multirow{2}{*}{$\begin{array}{c}\text { Main } \\
\text { effects }\end{array}$} \\
\hline & Control & $\mathrm{FC}$ & Control & $\mathrm{FC}$ & \\
\hline $16: 0$ & $20.37(0.11)$ & $20.50(0.16)$ & $20.19(0.13)$ & $20.47(0.12)$ & \\
\hline $18: 0$ & $16.69(0.07)$ & $16.45(0.14)$ & $16.95(0.17)$ & $16.77(0.12)$ & $\mathrm{G}$ \\
\hline $18: \ln 9$ & $15.27(0.08)$ & $16.26(0.12)$ & $15.08(0.12)$ & $16.02(0.08)$ & $\mathrm{D}, \mathrm{G}$ \\
\hline $20: 4 n 6$ & $8.35(0.08)$ & $6.32(0.08)$ & $8.34(0.06)$ & $6.47(0.05)$ & D \\
\hline $22: 6 n 3$ & $12.43(0.14)$ & $13.85(0.18)$ & $12.43(0.13)$ & $14.44(0.17)$ & $\mathrm{D},(\mathrm{D} \times \mathrm{G})$ \\
\hline SFA & $39.26(0.12)$ & $39.06(0.30)$ & $39.38(0.28)$ & $39.19(0.20)$ & \\
\hline MUFA & $24.01(0.22)$ & $25.07(0.22)$ & $23.82(0.21)$ & $24.53(0.17)$ & $\mathrm{D}$ \\
\hline PUFA & $25.71(0.23)$ & $24.82(0.21)$ & $25.92(0.22)$ & $25.53(0.18)$ & $\mathrm{D}, \mathrm{G}$ \\
\hline n6 & $12.73(0.12)$ & $9.84(0.10)$ & $12.95(0.15)$ & $9.94(0.11)$ & $\mathrm{D}$ \\
\hline n3 & $12.98(0.18)$ & $14.98(0.22)$ & $12.97(0.19)$ & $15.60(0.19)$ & $\mathrm{D}$ \\
\hline
\end{tabular}

$(\mathrm{F}(3,23)=139.00 ; p<0.001)$, while they increased the n3 PUFAs $(\mathrm{F}(3,23)=68.29 ; p<0.001)$ including DHA $(\mathrm{F}(3,23)=58.93 ; p<0.001)$.

\section{DISCUSSION}

The present results indicate not only that dietary intervention can affect $\mathrm{AD}$-like pathology in transgenic
$\mathrm{A} \beta \mathrm{PP} / \mathrm{PS} 1$ mice, but also that dietary composition, i.e., the simultaneous presence of specific nutrients, is an important factor in determining their efficacy. The specific multi-nutrient enriched FC diet was shown to reduce several pathology-related measures, including total brain $A \beta_{42}$ and $A \beta_{40}$ levels as measured by ELISA. In addition, by applying immunohistochemical techniques and a stereological approach to determine brain plaque burden, it was shown that 
Table 5

Relative amounts of the major individual fatty acids and their classes in the lipid fraction of the brain homogenates from experiment B. Data are expressed as means, with SEMs within parentheses. Statistically significant main effects of Diets (D) are indicated at the right hand side. Post-hoc comparisons indicated that both DHA-containing diets (DHA and DHA + UMP) differed from the remaining diets (Control and UMP)

\begin{tabular}{|c|c|c|c|c|c|}
\hline \multirow[t]{2}{*}{ Expt. B } & \multicolumn{4}{|c|}{ Transgenic } & \multirow{2}{*}{$\begin{array}{l}\text { Main } \\
\text { effects }\end{array}$} \\
\hline & Control & DHA & UMP & $\overline{\text { DHA UMP }}$ & \\
\hline $16: 0$ & $20.19(0.13)$ & $20.45(0.21)$ & $20.69(0.26)$ & $20.38(0.21)$ & \\
\hline $18: 0$ & $16.95(0.17)$ & $16.64(0.11)$ & $17.20(0.19)$ & $16.62(0.10)$ & $\mathrm{D}$ \\
\hline $18: \ln 9$ & $15.08(0.12)$ & $16.00(0.21)$ & $14.96(0.07)$ & $15.97(0.14)$ & $\mathrm{D}$ \\
\hline $20: 4 n 6$ & $8.34(0.06)$ & $6.50(0.13)$ & $8.38(0.07)$ & $6.45(0.11)$ & $\mathrm{D}$ \\
\hline $22: 6 n 3$ & $12.43(0.13)$ & $14.40(0.22)$ & $12.48(0.12)$ & $14.59(0.17)$ & $\mathrm{D}$ \\
\hline SFA & $39.38(0.28)$ & $39.11(0.28)$ & $39.97(0.40)$ & $39.04(0.27)$ & \\
\hline MUFA & $23.82(0.21)$ & $24.48(0.42)$ & $23.55(0.15)$ & $24.55(0.32)$ & $\mathrm{D}$ \\
\hline PUFA & $25.92(0.22)$ & $25.57(0.26)$ & $25.99(0.14)$ & $25.56(0.23)$ & \\
\hline n6 & $12.95(0.15)$ & $9.99(0.18)$ & $12.93(0.09)$ & $9.88(0.12)$ & $\mathrm{D}$ \\
\hline n3 & $12.97(0.19)$ & $15.58(0.23)$ & $13.06(0.12)$ & $15.67(0.20)$ & $\mathrm{D}$ \\
\hline
\end{tabular}

this multi-nutrient enrichment affected both amyloid plaque burden and degenerative burden in different brain structures. FC-induced reductions reached statistical significance for amyloid plaque burden in the hippocampus and for degenerative burden in the surrounding neocortex. These findings are in line with and extend our recent findings obtained in the $A \beta$ infusion model [21], by showing that FC diet may not only affect the $\mathrm{A} \beta$-induced membrane toxicity and neurodegeneration, but also the membrane-bound production of $A \beta$. In contrast, diets that were only enriched in DHA, UMP, or their combination yielded non-significant changes in amyloid plaque burden and degenerative burden in hippocampus and neocortex in these mice, although the UMP diet did reduce brain $A \beta_{40}$ levels. It should be noted that the DHA diet and the DHA + UMP diet were equally effective in raising brain DHA levels as the FC diet. Together these data indicate that the multi-nutrient enrichment by FC is effective in reducing pathological changes in the A $\beta P P / P S 1$ model, and that the effects of this dietary intervention are not easily attributed to one or more of its individual components.

Since especially some animals on the DHA diet died over the course of the study, this group was left with a relative small number of subjects. It is possible that this may have hampered us to observe statistically significant effects of the diet on AD-like pathology compared to Controls. Nevertheless, in experiment $B$ the largest differences were found between the DHA + UMP diet and the DHA or UMP only diets, underlining the importance of dietary context. This importance of dietary context was further supported by the results of the a posteriori exploratory analyses showing that the FC diet was more effective in reducing $A \beta$ pathology than the combination of nutrients in the DHA + UMP diet.

Previously, various studies have examined the effects of single-nutrient dietary supplementation on brain amyloid in different transgenic mouse models of AD. A number of these studies focused on the effects of supplementation of DHA or DHA-containing fish oil, with variable outcome. In an early study, Lim and coworkers [43] reported that a high DHA diet significantly decreased amyloid burden in aged Tg2576 mice, but only as compared to a DHA-depleting diet. In 3xTg-AD mice, dietary supplementation of DHA reduced soluble, but not insoluble $A \beta$ levels using whole-brain homogenates [39]. However, a more recent study found no significant effects of DHA consumption on $A \beta$ pathologies in frontal cortex samples of 3xTg-AD mice [41]. Similarly, the present findings obtained with DHA in experiment $B$ are not at variance with previous observations in the A $\beta P P / P S 1$ model. In this model, some reductions of hippocampal $A \beta$ levels and/or hippocampal plaque load induced by fish oil containing diets have been reported [24], albeit not consistently [40]. In a series of experiments using long term dietary interventions in the A $\beta P P / P S 1$ model, it was shown that fish oil may reduce vascular $A \beta$ in the neocortex more readily than parenchymal $A \beta$ plaques in the hippocampus [44]. In addition, it was shown that the effectiveness of fish oil diets on reducing neocortical $A \beta$ plaque load in this model may depend on both the age at which the intervention is started and on the length of the intervention [45]. Importantly, the present data indicate that the effectiveness of fish oil containing diets also depends on the concomitant availability of additional nutrients. This observation is in line with a recent report suggesting that the influence of DHA 
on amyloid plaque formation may depend upon the composition of the diet in which it is supplied [42].

To date, the effects of UMP administration on ADlike pathology in mouse models have less extensively been investigated than those of DHA. Nevertheless, the effects of UMP in experiment $B$ were more pronounced than those of DHA and reached statistical significance for brain $A \beta_{40}$ levels. The underlying mechanism by which UMP may affect $A \beta$ production is unknown, but might involve changes in $\mathrm{A} \beta \mathrm{PP}$ processing. Oral intake of UMP has been shown to increase brain levels of UTP [46] that may activate brain $\mathrm{P} 2 \mathrm{Y}$ receptors $[47,48]$. In vitro studies have shown that $\mathrm{P} 2 \mathrm{Y} 2$ receptor activation by UTP resulted in enhanced non-amyloidogenic processing of A $\beta P P$ [49]. Such a shift in A $\beta P P$ processing would be expected to result in decreased $A \beta$ release.

In view of the separate effects of DHA and UMP observed in experiment $\mathrm{B}$, the results obtained with combined administration of DHA + UMP are surprising. Thus, whereas UMP reduced brain $A \beta_{40}$ levels as compared to Control diet, the combination of $\mathrm{DHA}+\mathrm{UMP}$ induced an increase in $\mathrm{A} \beta_{40}$ as compared to UMP diet. Similarly, the combination of DHA + UMP induced an increase in brain $\mathrm{A} \beta_{42}$ levels as compared to the DHA diet and the UMP diet, while non-significant reductions in brain $A \beta_{42}$ levels were observed with the single-nutrient diets. Similar tendencies were observed for plaque burden and degenerative burden in the hippocampus and the neocortex. These seemingly contrasting findings are not easily explained. However, the difference in effect on amyloid pathology induced by the DHA diet, the DHA + UMP diet, and the FC diet demonstrates that the effects of these nutritional interventions are not the mere sum of the effects of their individual components. Interestingly, all these three DHA-containing diets induced very similar changes in brain fatty acid profiles, with increases in DHA and oleic acid, and decreases in AA, despite differences in effects on pathology. First, these data show that increased brain levels of DHA are not sufficient to decrease $A \beta$ production, amyloid plaque burden and degeneration in A $\beta P P / P S 1$ mice. Second, these data indicate that the combined administration of nutrients may yield seemingly unexpected cumulative actions. Co-administration of the dietary precursors for phospholipid synthesis DHA, UMP, and choline has previously been shown to stimulate neuronal membrane synthesis and dendritic spine formation more than enrichment of a single precursor [16]. Whether the stimulation of membrane synthesis and spine formation may have increased $\mathrm{A} \beta \mathrm{PP}$ processing and subsequent $\mathrm{A} \beta$ production in the A $\beta P P / P S 1$ mice remains to be determined. Third, these data indicate that nutrients present in FC other than DHA and UMP contribute significantly to the overall effect of this multi-nutrient mixture on AD-like pathology. Indeed, several studies using single nutrient enrichment provide some, albeit weak, support for the potential beneficial effects of these nutrients. For instance, in line with the idea that antioxidants like vitamins $\mathrm{E}$ and $\mathrm{C}$ may improve the neuroprotective effects of DHA [50], vitamin E was shown to help reduce $\mathrm{A} \beta$ levels and amyloid deposition in young $\mathrm{Tg} 2576$ mice [51], although combined administration of vitamins $\mathrm{E}$ and $\mathrm{C}$ did not reduce amyloid deposition in A $\beta P P / P S 1$ mice [52]. Similarly, B-vitamin deficiency has sometimes been found to increase $A \beta$ levels and deposition in Tg2576 mice [53], but not always [54]. The effects of combined B-vitamins on $A \beta$ production may result from changes in $\beta$ - and $\gamma$-secretase activity [55]. In this respect there is an overlap in modes of action with those of nutrients like DHA [37], which may help to understand the efficacy of a multi-nutrient approach. An elegant example of the concerted action of the nutrients in FC on membrane bound G-protein coupled receptor functioning is provided by Savelkoul et al. [56].

In line with previous reports [22, 23, 57], we observed higher brain levels of $A \beta_{42}$ than $A \beta_{40}$ in young adult $\mathrm{A} \beta \mathrm{PP} / \mathrm{PS} 1$ animals of 6 months. Using an $A \beta_{42}$ antibody for immunohistochemistry, we also noted at this stage an anatomical differentiation in the development of amyloid plaques, showing higher levels of amyloid plaque burden in the neocortex than in the hippocampus. In the A $\beta P P / P S 1$ mice, degenerative staining displayed a similar anatomical differentiation and a close overlap with amyloid staining, supporting a link between $A \beta_{42}$ levels, amyloid plaque formation and neurotoxicity in these mice. In wild type mice we also observed some degenerative staining, and interestingly, the FC diet reduced neocortical neurodegeneration in wild type and transgenic animals to a similar extent, suggesting that the diet may have protective effects irrespective whether the degeneration is caused by amyloid toxicity.

The present effects obtained with the multi-nutrient enriched FC diet confirm and extend recent observations in the $A \beta$ infusion model [21], showing that the same FC diet reduced both the neuroanatomical and behavioral consequences of $A \beta$ toxicity. We now show that this multi-nutrient enrichment effectively reduces $A \beta$ production and $A D-$ like pathology in the A $\beta P P / P S 1$ mouse model, while enrichment with DHA, UMP, or their combination had little effect. Whether 
the observed reductions in pathology may contribute to the preservation of cognitive performance remains to be determined. It may however be speculated that the presently observed reductions in $A \beta$ production and amyloid-related neurodegeneration may be part of the mechanisms underlying observed improvements of memory performance following this multi-nutrient intervention in mild $\mathrm{AD}$ patients $[58,59]$. Additional studies investigating the effects of longer term dietary interventions on cognitive performance in A $\beta P P / P S 1$ mice, $\mathrm{AD}$ patients, and subjects with prodromal $\mathrm{AD}$ are currently ongoing.

\section{ACKNOWLEDGMENTS}

The authors thank Henk Arnts for his skillful assistance during the studies. The research leading to these results has received funding from the EU FP7 project LipiDiDiet, Grant Agreement No 211696. LMB, AAMK, MB, NvW, PJMS, MCdW, EMvdB, JWCS, RJJH, and PJGHK are employed by Nutricia Advanced Medical Nutrition, Danone Research, Centre for Specialised Nutrition.

Authors' disclosures available online (http://www.jalz.com/disclosures/view.php?id=1463).

\section{REFERENCES}

[1] Barberger-Gateau P, Letenneur L, Deschamps V, Peres K, Dartigues JF, Renaud S (2002) Fish, meat, and risk of dementia: Cohort study. BMJ 325, 932-933.

[2] Barberger-Gateau P, Raffaitin C, Letenneur L, Berr C, Tzourio C, Dartigues JF, Alperovitch A (2007) Dietary patterns and risk of dementia: The three-city cohort study. Neurology 69 , 1921-1930.

[3] Engelhart MJ, Geerlings MI, Ruitenberg A, van Swieten JC, Hofman A, Witteman JC, Breteler MM (2002) Dietary intake of antioxidants and risk of Alzheimer disease. JAMA 287, 3223-3229.

[4] Eskelinen MH, Ngandu T, Helkala EL, Tuomilehto J, Nissinen A, Soininen H, Kivipelto M (2008) Fat intake at midlife and cognitive impairment later in life: A population-based CAIDE study. Int J Geriatr Psychiatry 23, 741-747.

[5] Kalmijn S, Launer LJ, Ott A, Witteman JC, Hofman A, Breteler MM (1997) Dietary fat intake and the risk of incident dementia in the Rotterdam Study. Ann Neurol 42, 776-782.

[6] Munoz MA, Fito M, Marrugat J, Covas MI, Schroder H (2009) Adherence to the Mediterranean diet is associated with better mental and physical health. Br J Nutr 101, 1821-1827.

[7] Feart C, Samieri C, Rondeau V, Amieva H, Portet F, Dartigues JF, Scarmeas N, Barberger-Gateau P (2009) Adherence to a Mediterranean diet, cognitive decline, and risk of dementia. JAMA 302, 638-648.

[8] Scarmeas N, Stern Y, Tang MX, Mayeux R, Luchsinger JA (2006) Mediterranean diet and risk for Alzheimer's disease. Ann Neurol 59, 912-921.
[9] Isaac MG, Quinn R, Tabet N (2008) Vitamin E for Alzheimer's disease and mild cognitive impairment. Cochrane Database Syst Rev, CD002854.

[10] Lim W, Gammack J, Van Niekerk J, Dangour A (2006) Omega 3 fatty acid for the prevention of dementia. Cochrane Database Syst Rev, CD005379.

[11] Malouf R, Areosa Sastre A (2003) Vitamin B12 for cognition. Cochrane Database Syst Rev, CD004326.

[12] Malouf R, Grimley Evans J (2003) The effect of vitamin B6 on cognition. Cochrane Database Syst Rev, CD004393.

[13] Holguin S, Martinez J, Chow C, Wurtman R (2008) Dietary uridine enhances the improvement in learning and memory produced by administering DHA to gerbils. FASEB $J \mathbf{2 2}$, 3938-3946.

[14] Sakamoto T, Cansev M, Wurtman RJ (2007) Oral supplementation with docosahexaenoic acid and uridine- $5^{\prime}$ monophosphate increases dendritic spine density in adult gerbil hippocampus. Brain Res 1182, 50-59.

[15] Wurtman RJ, Ulus IH, Cansev M, Watkins CJ, Wang L, Marzloff G (2006) Synaptic proteins and phospholipids are increased in gerbil brain by administering uridine plus docosahexaenoic acid orally. Brain Res 1088, 83-92.

[16] Wurtman RJ, Cansev M, Sakamoto T, Ulus IH (2009) Use of phosphatide precursors to promote synaptogenesis. Annu Rev Nutr 29, 59-87.

[17] Nitsch RM, Blusztajn JK, Pittas AG, Slack BE, Growdon JH, Wurtman RJ (1992) Evidence for a membrane defect in Alzheimer disease brain. Proc Natl Acad Sci U S A 89, 1671-1675.

[18] Pettegrew JW, Panchalingam K, Hamilton RL, McClure RJ (2001) Brain membrane phospholipid alterations in Alzheimer's disease. Neurochem Res 26, 771-782.

[19] Selkoe DJ (2002) Alzheimer's disease is a synaptic failure. Science 298, 789-791.

[20] Terry RD (2006) Alzheimer's disease and the aging brain. J Geriatr Psychiatry Neurol 19, 125-128.

[21] De Wilde MC, Penke B, van der Beek EM, Kuipers AAM, Kamphuis PJ, Broersen LM (2011) Neuroprotective effects of a specific multi-nutrient intervention against $A \beta_{42}$-induced toxicity in rats. $J$ Alzheimers Dis 27, 327-339.

[22] Jankowsky JL, Fadale DJ, Anderson J, Xu GM, Gonzales V, Jenkins NA, Copeland NG, Lee MK, Younkin LH, Wagner SL, Younkin SG, Borchelt DR (2004) Mutant presenilins specifically elevate the levels of the 42 residue beta-amyloid peptide in vivo: Evidence for augmentation of a 42-specific gamma secretase. Hum Mol Genet 13, 159170.

[23] Wang J, Tanila H, Puolivali J, Kadish I, van Groen T (2003) Gender differences in the amount and deposition of amyloidbeta in APPswe and PS1 double transgenic mice. Neurobiol Dis 14, 318-327.

[24] Oksman M, Iivonen H, Hogyes E, Amtul Z, Penke B, Leenders I, Broersen L, Lutjohann D, Hartmann T, Tanila H (2006) Impact of different saturated fatty acid, polyunsaturated fatty acid and cholesterol containing diets on beta-amyloid accumulation in APP/PS1 transgenic mice. Neurobiol Dis 23, 563-572.

[25] de Olmos JS, Beltramino CA, de Olmos de Lorenzo S (1994) Use of an amino-cupric-silver technique for the detection of early and semiacute neuronal degeneration caused by neurotoxicants, hypoxia, and physical trauma. Neurotoxicol Teratol 16, 545-561.

[26] Switzer RC 3rd (2000) Application of silver degeneration stains for neurotoxicity testing. Toxicol Pathol 28, 70-83. 
[27] Kennedy EP, Weiss SB (1956) The function of cytidine coenzymes in the biosynthesis of phospholipides. J Biol Chem 222, 193-214.

[28] Anderson GJ, Connor WE, Corliss JD (1990) Docosahexaenoic acid is the preferred dietary n-3 fatty acid for the development of the brain and retina. Pediatr Res 27, 89-97.

[29] Hashimoto M, Hossain S, Tanabe Y, Kawashima A, Harada T, Yano T, Mizuguchi K, Shido O (2009) The protective effect of dietary eicosapentaenoic acid against impairment of spatial cognition learning ability in rats infused with amyloid beta(140). J Nutr Biochem 20, 965-973.

[30] van Wijk N, Watkins CJ, Bohlke M, Maher TJ, Hageman RJ, Kamphuis PJ, Broersen LM, Wurtman RJ (2012) Plasma choline concentration varies with different dietary levels of vitamins B6, B12 and folic acid in rats maintained on cholineadequate diets. Br J Nutr 107, 1408-1412.

[31] van Wijk N, Watkins CJ, Hageman RJ, Sijben JW, Kamphuis PJ, Wurtman RJ, Broersen LM (2012) Combined dietary folate, vitamin B-12, and vitamin B-6 intake influences plasma docosahexaenoic acid concentration in rats. Nutr Metab (Lond) 9, 49.

[32] Liu SY, Tardi PG, Choy PC, Man RY (1993) Effects of selenium supplement on the de novo biosynthesis of glycerolipids in the isolated rat heart. Biochim Biophys Acta 1170, 307-313.

[33] Soderberg M, Edlund C, Kristensson K, Dallner G (1991) Fatty acid composition of brain phospholipids in aging and in Alzheimer's disease. Lipids 26, 421-425.

[34] Tully AM, Roche HM, Doyle R, Fallon C, Bruce I, Lawlor B, Coakley D, Gibney MJ (2003) Low serum cholesteryl esterdocosahexaenoic acid levels in Alzheimer's disease: A casecontrol study. Br J Nutr 89, 483-489.

[35] Clarke R, Smith AD, Jobst KA, Refsum H, Sutton L, Ueland PM (1998) Folate, vitamin B12, and serum total homocysteine levels in confirmed Alzheimer disease. Arch Neurol 55, 14491455.

[36] Rinaldi P, Polidori MC, Metastasio A, Mariani E, Mattioli P, Cherubini A, Catani M, Cecchetti R, Senin U, Mecocci P (2003) Plasma antioxidants are similarly depleted in mild cognitive impairment and in Alzheimer's disease. Neurobiol Aging 24, 915-919.

[37] Grimm MO, Kuchenbecker J, Groesgen S, Burg VK, Hundsdoerfer B, Rothhaar TL, Friess P, de Wilde MC, Broersen LM, Penke B, Peter M, Vigh L, Grimm HS, Hartmann T (2011) Docosahexaenoic acid reduces amyloid $\{$ beta $\}$ production via multiple, pleiotropic mechanism. J Biol Chem 286, 14028-14039.

[38] Calon F, Lim GP, Yang F, Morihara T, Teter B, Ubeda O, Rostaing P, Triller A, Salem N Jr, Ashe KH, Frautschy SA, Cole GM (2004) Docosahexaenoic acid protects from dendritic pathology in an Alzheimer's disease mouse model. Neuron 43, 633-645.

[39] Green KN, Martinez-Coria H, Khashwji H, Hall EB, Yurko-Mauro KA, Ellis L, LaFerla FM (2007) Dietary docosahexaenoic acid and docosapentaenoic acid ameliorate amyloid-beta and tau pathology via a mechanism involving presenilin 1 levels. J Neurosci 27, 4385-4395.

[40] Arendash GW, Jensen MT, Salem N Jr, Hussein N, Cracchiolo J, Dickson A, Leighty R, Potter H (2007) A diet high in omega-3 fatty acids does not improve or protect cognitive performance in Alzheimer's transgenic mice. Neuroscience 149, 286-302.

[41] Arsenault D, Julien C, Tremblay C, Calon F (2011) DHA improves cognition and prevents dysfunction of entorhinal cortex neurons in 3xTg-AD mice. PLoS One 6, e17397.
[42] Amtul Z, Keet M, Wang L, Merrifield P, Westaway D, Rozmahel RF (2011) DHA supplemented in peptamen diet offers no advantage in pathways to amyloidosis: Is it time to evaluate composite lipid diet? PLoS One 6, e24094.

[43] Lim GP, Calon F, Morihara T, Yang F, Teter B, Ubeda O, Salem $\mathrm{N} \mathrm{Jr}$, Frautschy SA, Cole GM (2005) A diet enriched with the omega-3 fatty acid docosahexaenoic acid reduces amyloid burden in an aged Alzheimer mouse model. J Neurosci 25, 3032-3040.

[44] Hooijmans CR, Rutters F, Dederen PJ, Gambarota G, Veltien A, van Groen T, Broersen LM, Lutjohann D, Heerschap A, Tanila H, Kiliaan AJ (2007) Changes in cerebral blood volume and amyloid pathology in aged Alzheimer APP/PS1 mice on a docosahexaenoic acid (DHA) diet or cholesterol enriched Typical Western Diet (TWD). Neurobiol Dis 28, 16-29.

[45] Hooijmans CR, Van der Zee CE, Dederen PJ, Brouwer KM, Reijmer YD, van Groen T, Broersen LM, Lutjohann D, Heerschap A, Kiliaan AJ (2009) DHA and cholesterol containing diets influence Alzheimer-like pathology, cognition and cerebral vasculature in APPswe/PS1dE9 mice. Neurobiol Dis 33, 482-498.

[46] Cansev M, Watkins CJ, van der Beek EM, Wurtman RJ (2005) Oral uridine- $5^{\prime}$-monophosphate (UMP) increases brain CDPcholine levels in gerbils. Brain Res 1058, 101-108.

[47] Chen CC, Chen WC (1997) P2Y receptor linked to phospholipase C: Stimulation of neuro 2A cells by UTP and ATP and possible regulation by protein kinase $\mathrm{C}$ subtype epsilon. J Neurochem 69, 1409-1416.

[48] Lustig KD, Shiau AK, Brake AJ, Julius D (1993) Expression cloning of an ATP receptor from mouse neuroblastoma cells. Proc Natl Acad Sci U S A 90, 5113-5117.

[49] Camden JM, Schrader AM, Camden RE, Gonzalez FA, Erb L, Seye CI, Weisman GA (2005) P2Y2 nucleotide receptors enhance alpha-secretase-dependent amyloid precursor protein processing. J Biol Chem 280, 18696-18702.

[50] Cole GM, Ma QL, Frautschy SA (2009) Omega-3 fatty acids and dementia. Prostaglandins Leukot Essent Fatty Acids 81, 213-221.

[51] Sung S, Yao Y, Uryu K, Yang H, Lee VM, Trojanowski JQ, Pratico D (2004) Early vitamin E supplementation in young but not aged mice reduces Abeta levels and amyloid deposition in a transgenic model of Alzheimer's disease. FASEB $J$ 18, 323-325.

[52] Harrison FE, Allard J, Bixler R, Usoh C, Li L, May JM, McDonald MP (2009) Antioxidants and cognitive training interact to affect oxidative stress and memory in APP/PSEN1 mice. Nutr Neurosci 12, 203-218.

[53] Zhuo JM, Pratico D (2010) Acceleration of brain amyloidosis in an Alzheimer's disease mouse model by a folate, vitamin B6 and B12-deficient diet. Exp Gerontol 45, 195-201.

[54] Bernardo A, McCord M, Troen AM, Allison JD, McDonald MP (2007) Impaired spatial memory in APP-overexpressing mice on a homocysteinemia-inducing diet. Neurobiol Aging 28, 1195-1205.

[55] Fuso A, Nicolia V, Cavallaro RA, Ricceri L, D'Anselmi F, Coluccia P, Calamandrei G, Scarpa S (2008) Bvitamin deprivation induces hyperhomocysteinemia and brain S-adenosylhomocysteine, depletes brain Sadenosylmethionine, and enhances PS1 and BACE expression and amyloid-beta deposition in mice. Mol Cell Neurosci 37, 731-746.

[56] Savelkoul PJM, Janieckova H, Kuipers AAM, Hageman RJJ, Kamphuis PJ, Dolezal V, Broersen LM (2012) A specific multi-nutrient formulation enhances M1 muscarinic 
acetylcholine receptor responses in vitro. J Neurochem 120, 631-640.

[57] Borchelt DR, Thinakaran G, Eckman CB, Lee MK, Davenport F, Ratovitsky T, Prada CM, Kim G, Seekins S, Yager D, Slunt HH, Wang R, Seeger M, Levey AI, Gandy SE, Copeland NG, Jenkins NA, Price DL, Younkin SG, Sisodia SS (1996) Familial Alzheimer's disease-linked presenilin 1 variants elevate Abeta1-42/1-40 ratio in vitro and in vivo. Neuron 17, 1005-1013.

[58] Scheltens P, Kamphuis PJ, Verhey FR, Olde Rikkert MG, Wurtman RJ, Wilkinson D, Twisk JW, Kurz A (2010) Efficacy of a medical food in mild Alzheimer's disease: A randomized, controlled trial. Alzheimers Dement 6, 1-10 e11.

[59] Scheltens P, Twisk JW, Blesa R, Scarpini E, von Arnim CA, Bongers A, Harrison J, Swinkels SH, Stam CJ, de Waal H, Wurtman RJ, Wieggers RL, Vellas B, Kamphuis PJ (2012) Efficacy of souvenaid in mild Alzheimer's disease: Results from a randomized, controlled trial. J Alzheimers Dis 31, 225236. 